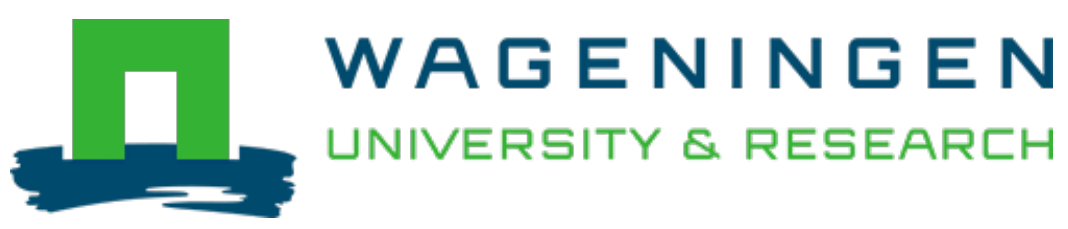

\title{
Food processing and breeding strategies for coeliac-safe and healthy wheat products
}

\author{
Food Research International \\ Jouanin, Aurélie; Gilissen, Luud J.W.J.; Boyd, Lesley A.; Cockram, James; Leigh, Fiona J. et al \\ https://doi.org/10.1016/j.foodres.2017.04.025
}

This article is made publicly available in the institutional repository of Wageningen University and Research, under the terms of article $25 \mathrm{fa}$ of the Dutch Copyright Act, also known as the Amendment Taverne. This has been done with explicit consent by the author.

Article 25 fa states that the author of a short scientific work funded either wholly or partially by Dutch public funds is entitled to make that work publicly available for no consideration following a reasonable period of time after the work was first published, provided that clear reference is made to the source of the first publication of the work.

This publication is distributed under The Association of Universities in the Netherlands (VSNU) 'Article $25 \mathrm{fa}$ implementation' project. In this project research outputs of researchers employed by Dutch Universities that comply with the legal requirements of Article $25 \mathrm{fa}$ of the Dutch Copyright Act are distributed online and free of cost or other barriers in institutional repositories. Research outputs are distributed six months after their first online publication in the original published version and with proper attribution to the source of the original publication.

You are permitted to download and use the publication for personal purposes. All rights remain with the author(s) and / or copyright owner(s) of this work. Any use of the publication or parts of it other than authorised under article $25 \mathrm{fa}$ of the Dutch Copyright act is prohibited. Wageningen University \& Research and the author(s) of this publication shall not be held responsible or liable for any damages resulting from your (re)use of this publication.

For questions regarding the public availability of this article please contact openscience.library@,wur.nl 


\title{
Food processing and breeding strategies for coeliac-safe and healthy wheat products
}

\author{
Aurélie Jouanin $^{\mathrm{a}, \mathrm{b}}$, Luud J.W.J. Gilissen ${ }^{\mathrm{a}}$, Lesley A. Boyd ${ }^{\mathrm{b}}$, James Cockram ${ }^{\mathrm{b}}$, Fiona J. Leigh ${ }^{\mathrm{b}}$, \\ Emma J. Wallington $^{\mathrm{b}}$, Hetty C. van den Broeck ${ }^{\mathrm{a}}$, Ingrid M. van der Meer ${ }^{\mathrm{a}}$, Jan G. Schaart ${ }^{\mathrm{a}}$, \\ Richard G.F. Visser ${ }^{\mathrm{a}}$, Marinus J.M. Smulders ${ }^{\mathrm{a}, *}$ \\ a Wageningen University \& Research, Wageningen, The Netherlands \\ b NIAB, Cambridge CB3 OLE, UK
}

\section{A R T I C L E I N F O}

\section{Keywords:}

Gluten

Gliadin

$\mathrm{T}$ cell epitope

Coeliac disease

Plant breeding

Food processing

Mutation breeding

Genome editing

\begin{abstract}
A B S T R A C T
A strict gluten-free diet is currently the only treatment for the 1-2\% of the world population who suffer from coeliac disease (CD). However, due to the presence of wheat and wheat derivatives in many food products, avoiding gluten consumption is difficult. Gluten-free products, made without wheat, barley or rye, typically require the inclusion of numerous additives, resulting in products that are often less healthy than gluten-based equivalents. Here, we present and discuss two broad approaches to decrease wheat gluten immunogenicity for CD patients. The first approach is based on food processing strategies, which aim to remove gliadins or all gluten from edible products. We find that several of the candidate food processing techniques to produce low glutenimmunogenic products from wheat already exist. The second approach focuses on wheat breeding strategies to remove immunogenic epitopes from the gluten proteins, while maintaining their food-processing properties. A combination of breeding strategies, including mutation breeding and possibly genome editing, will be necessary to produce coeliac-safe wheat. Individuals suffering from $\mathrm{CD}$ and people genetically susceptible who may develop CD after prolonged gluten consumption would benefit from reduced CD-immunogenic wheat. Although the production of healthy and less CD-toxic wheat varieties and food products will be challenging, increasing global demand may require these issues to be addressed in the near future by food processing and cereal breeding companies.
\end{abstract}

\section{Introduction}

Wheat forms the basis of a diverse range of staple foods globally, which includes bread and bakery items in addition to other products such as alcoholic beverages and food additives. Two major storage protein families are present in wheat grains: glutenins and gliadins (belonging to glutelins and prolamins, respectively), which are collectively known as gluten. The qualitative and quantitative properties of wheat gluten are important factors for baking quality. Despite its predominance in the human diet, wheat can cause allergies and/or intolerances after consumption in susceptible individuals (Fasano, 2006). Wheat contains immunogenic proteins, but the prevalence of wheat allergy, which is mediated by IgE antibodies, is low (Zuidmeer et al., 2008; Gilissen, van der Meer, and Smulders, 2014). However, gluten can also trigger intolerance reactions in $1-2 \%$ of the human population, the most common of which is coeliac disease (CD) (Mäki et al., 2003; Rewers, 2005; Catassi, Gatti, and Fasano, 2014; Vriezinga,
Schweizer, Koning, and Mearin, 2015).

$\mathrm{CD}$ is a chronic inflammation of the small intestine, which leads to a variety of symptoms that can include malnutrition, bowel disorders, skin, bone, nerve, and muscle problems. It is induced by epitopes (peptide sequences of nine amino acids) present in gluten proteins from wheat, barley and rye. These epitopes are bound by human leucocyte antigen sub-units (HLA-DQ2 or HLA-DQ8) located on antigen presenting cells in humans, which are subsequently recognized by $\mathrm{T}$ cells, triggering an immune reaction (for reviews see Fasano, 2009; Koning, 2012). CD develops in genetically predisposed individuals, and is induced by gluten ingestion. A strict gluten-free diet is currently the only treatment to stop the immune reaction and inflammation, allowing the intestine to recover, after which the symptoms gradually disappear.

Avoiding consumption of gluten is difficult to do in practice, due to the presence of wheat derivatives in many supermarket products (Atchison, Head, and Gates, 2010). Therefore there is a need for new strategies to create food products with low gluten immunogenicity.

\footnotetext{
* Corresponding author.

E-mail address: rene.smulders@wur.nl (M.J.M. Smulders).
} 


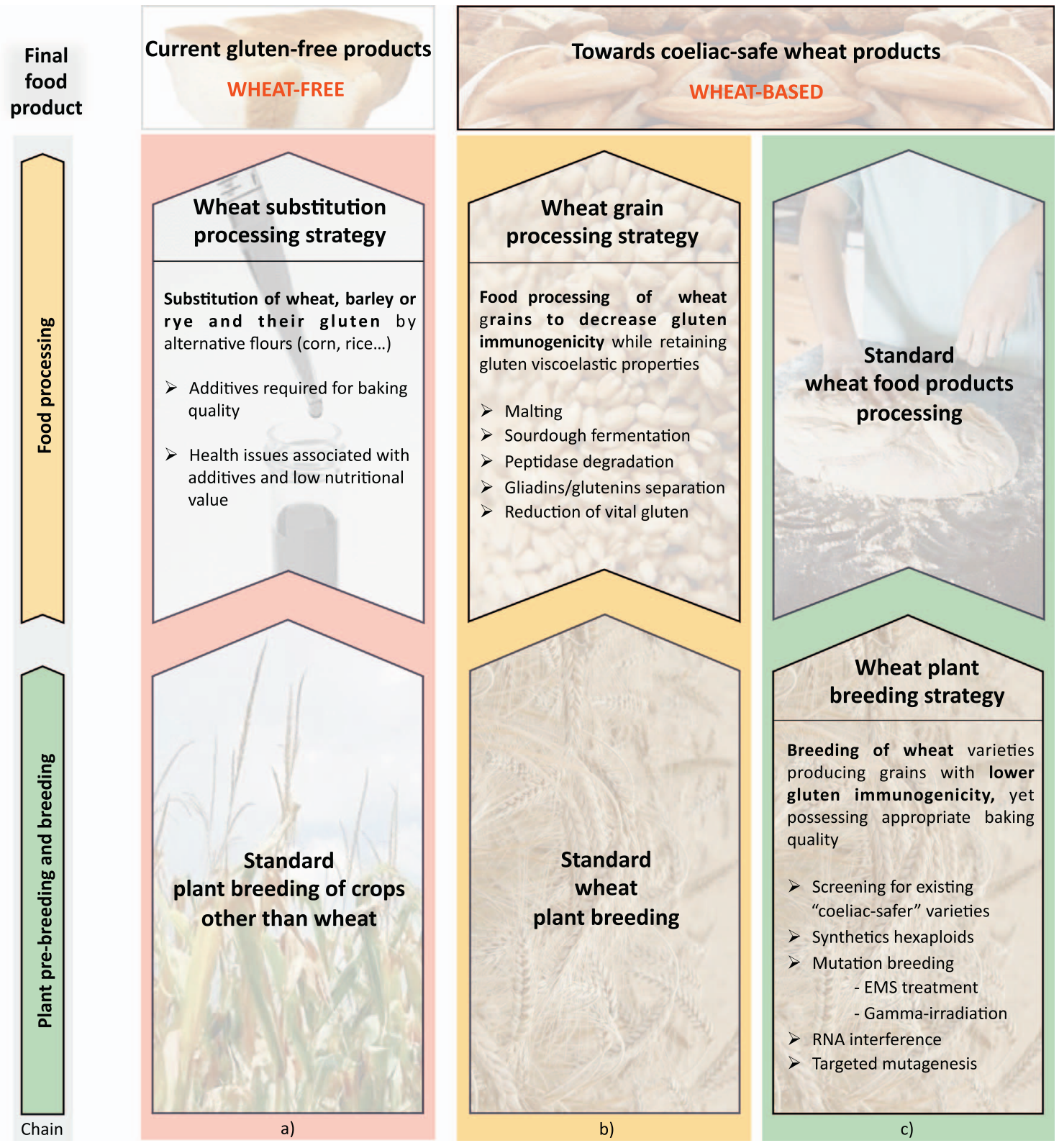

Fig. 1. Food supply chains producing gluten-free or coeliac-safe(r) products.

Here, we summarise several strategies to decrease wheat gluten toxicity for CD patients, based on food processing and on wheat breeding (Fig. 1). The food processing strategies aim at removing gliadins or whole gluten from edible products (Gilissen et al. 2016b) whereas the wheat breeding strategies focus on the removal of immunogenic epitopes from the gluten proteins, while potentially maintaining their food-technological properties (Smulders et al., 2015; Shewry and Tatham, 2016). If successful, the latter strategy may result in food products considered coeliac-safe, despite containing large amounts of gluten, which would require alternative labelling from the term 'glutenfree'. A comparison of the applicability of these approaches, in terms of technical and economic aspects, is presented. Two groups of people may benefit especially from food products derived from such reduced CD-immunogenic wheat: (1) individuals suffering from $\mathrm{CD}$, whether they are already or not yet diagnosed as CD patient, and (2) genetically predisposed individuals who may develop $\mathrm{CD}$ after prolonged wheat or gluten consumption.
2. Food processing-related strategies to manufacture gluten-free products or to lower the content of CD epitopes

Wheat gluten is a polymer composed of two types of proteins: glutenins and gliadins. The type of HMW subunits and the ratio of glutenins and gliadins determine the viscoelasticity properties required for bread, cakes or other baking products (Weegels, van de Pijpekamp, Graveland, Hamer, and Schofield, 1996; Shewry et al., 2009). The high and low molecular weight glutenin subunits (HMW-glutenins and LMW-glutenins) form a strong glutenin macro polymer (GMP) network, formed by inter-chain disulphide bonds, which determines dough elasticity. The monomeric gliadin proteins ( $\alpha / \beta$-gliadins, $\gamma$-gliadins and $\omega$-gliadins) are linked to the GMP and can be envisaged to 'dilute' the strength of the GMP, thus influencing dough viscosity (Shewry, 2009). The glutenins are the less immunogenic gluten proteins for CD. The monomeric gliadin proteins $(\alpha / \beta$-gliadins, $\gamma$-gliadins and $\omega$-gliadins) are the most immunogenic.

Two types of products can be generated during food production: gluten-free products made without ingredients from wheat, barley or 
rye (Fig. 1a), or products with low gluten immunogenicity based on the processing of these cereal grains to remove the immunogenic gluten fraction (Fig. 1b) (as reviewed by Kucek, Veenstra, Amnuaycheewa, and Sorrells, 2015). Food products can be labelled as 'gluten-free' as long as they contain $<20 \mathrm{ppm}$ of gluten (Saturni, Ferretti, and Bacchetti, 2010).

\subsection{Gluten-free products made without ingredients from wheat, barley and rye}

With increasing numbers of patients with $\mathrm{CD}$ being diagnosed, the gluten-free market is becoming more important, and gluten-free products are increasingly found on grocery shop shelves. Such products generally do not contain any wheat, barley or rye, but include several additives (Fig. 1a) to recreate the viscoelastic properties of gluten present in these cereal grains (as summarised by Gustafson, 2016).

\subsubsection{Current composition of gluten-free products}

Currently commercial gluten-free bread is usually made from a mixture of flours, including maize, rice, sorghum and oat. Oat can be consumed safely by CD patients without a daily limit (Kaukinen, Collin, Huhtala, and Mäki, 2013; Hardy, Tye-Din, and Stewart, 2015; Gilissen et al., 2016a and references therein). Alternatively, flour from pseudocereals (such as amaranth, buckwheat and quinoa), legumes and nuts have been proposed as new candidates for gluten-free products.

Issues encountered with these gluten-free flours are their lack of viscoelasticity and their low ability to retain water and $\mathrm{CO}_{2}$, the properties responsible for dough rising conferred by the gluten network. Starch may be added to increase viscosity and provide some binding abilities to the dough (Horstmann et al., 2016). Starches from potato, corn, rice and cassava (tapioca) are mostly used. Hydrocolloids, also known as gums, are also important additives in gluten-free baking products. They are used as substitute for glutenins to confer elasticity to the dough, as well as gas and moisture retention for higher loaf volumes and longer shelf life. Inulin, xanthan, guar gum, and hydroxypropyl methylcellulose (HPMC) are the most commonly used hydrocolloids in gluten-free bread. Protein concentrates such as soybean, egg and whey proteins are also used for their gelling properties, contributing to dough quality improvement. The addition of lipids, such as sunflower and safflower oil, retards the staling process, due to the gas-retaining properties of polar lipids (Hardy et al., 2015). Additionally, emulsifiers such as glycerol monostearate and lecithin are commonly used to reduce staling and to increase shelf-life. High salt content is often used to improve taste, texture and bread stability (Belz, 2016). The addition of dietary fibre through incorporation of oat or rice bran could become a solution to compensate for the low fibre content of gluten-free bread (Gilissen et al. 2016b). Rice bran also appears to improve rheology and sensory aspects of gluten-free bread, whereas dough acidification with acetic, citric, or lactic acid, or monosodium phosphate can also help improve bread volume.

\subsubsection{Health issues associated with current gluten-free products}

Gluten-free bread thus contains far more additives than standard wheat bread. As a result, regular consumption of gluten-free bread may in itself cause health issues, e.g. the mineral content can be very low, leading to iron and calcium deficiency, and despite the inclusion of protein additives for dough improvement, it is a relatively poor source of protein. Gluten-free bread is usually low in fibre, which decreases the sensation of satiety; in contrast, it is rich in starch, thereby enhancing the risk of hyperglycaemia and diabetes. The high level of salt in glutenfree bread is a risk for cardiovascular and renal disease. In addition to being high in lipids, gluten-free products contain trans fatty acids, which may provoke metabolic imbalance (Caponio, Summo, Clodoveo, and Pasqualone, 2008). Several countries try to reduce or eliminate them from food products. Fructan-type inulin is used in gluten-free bread as a hydrocolloid but is known to be a possible cause of irritable bowel syndrome (IBS) (Capriles and Arêas, 2014). IBS is mainly caused by fermentable oligosaccharides, disaccharides, monosaccharides and polyols (FODMAPs) such as fructan, a fructose polymer. Since fructans are present in the wheat grain, IBS is often associated with wheat as non-coeliac gluten sensitivity or non-coeliac wheat sensitivity (NCGS), and is sometimes wrongly auto-diagnosed as CD. While a low FODMAPs diet will usually decrease IBS symptoms, some gluten-free bread products containing inulin may not be suitable for these patients. In such cases, it is important to be diagnosed with the correct disorder. Nonetheless, based on the frequency of people with clinical bowel complaints that appear to improve under a gluten-free diet, the prevalence of NCGS might be as high as 6\% of the population (Gilissen et al., 2014), but more recent evidence suggests that 'true' NCGS is only slightly $>1 \%$ of the population (Catassi, 2015). Although no biomarkers have been identified yet, a state of systemic immune activation in conjunction with a suggested compromised intestinal epithelium could be observed in a subset of individuals with NCGS (Uhde et al., 2016). In addition to individuals diagnosed with CD or IBS, other consumers have actively decided to avoid wheat and gluten based on personal choice. However, such choices are often made following self-diagnosis based on personal health-related preference, rather than for clear medical reasons, despite the dietary concerns described above.

\subsubsection{Gluten contamination elimination diet (GCED)}

Some coeliac patients have persistent symptoms and villous atrophy despite strict adherence to a gluten-free diet. They are referred to as having 'non-responsive CD'. Some non-responding CD patients may react to minute amounts of gluten, likely present as contaminants in processed gluten-free foods. For example, industrial conversion of wheat starch into other food-grade carbohydrates may not eliminate all gluten (Scherf, Wieser, and Koehler, 2016). Therefore, foods containing these modified carbohydrates may still contain very low levels of stable, and potentially immunogenic, gluten. Furthermore, when chemically deamidated gluten protein, which is even more immunogenic than natural gluten proteins, is used for increased emulsifying applications (Wu, Nakai, and Powrie, 1976) it may be undetectable in the R5 monoclonal antibody assay used for routine gluten screening by commercial companies (Kanerva, Brinck, SontagStrohm, Salovaara, and Loponen, 2011). These undetected deamidated gluten fractions can also contribute to contamination of food labelled as 'gluten-free'.

Over $80 \%$ of the non-responsive patients showed health improvement under a 'gluten contamination elimination diet' (GCED), that includes only fresh and unprocessed foods. These patients were able to return to a traditional gluten-free diet without return of symptoms (Hollon et al., 2015). A subset of 'non-responsive CD' patients do not show any decrease in symptoms under GCED, and therefore suffer from true 'refractory CD' (RCD).

\subsection{Development of wheat-based products with low gluten immunogenicity}

Due to the low dietary value and health risks associated with nonwheat based gluten-free products, alternative food processing methods for wheat are being investigated (Fig. 1b). The main aim is to use wheat (conserving the rheological properties conferred by the glutenins), while removing the most immunogenic gluten fraction (the gliadins). This approach would decrease the need for additives to reach adequate dough quality and dietary values, thus improving the healthiness of gluten-free or 'gluten-safe' products.

\subsubsection{Malting}

The malting process is not only relevant for brewing beer, but also for the baking sector. Malting represents the first step in seed germination, during which amylase enzymes become active, degrading starch into maltose to provide the source of energy for the embryo to germinate. Malting produces higher amounts of maltose, which en- 
hances further fermentation. In addition, endogenous proteolytic enzymes in the grain degrade storage proteins (i.e. gluten), releasing amino acids that are used by the growing seedling. Gliadins become degraded through the activity of proteases (Bigiarini et al., 1995). Because of this degradation process, in practice many brands of beer are technically gluten-free or contain only small amounts of gluten.

Malting has been used for many years to add flavour and crust colour to bread, and can even enhance sourdough fermentation when the malting process is not fully stopped. It has been shown that malted and fermented wheat sourdough effectively degrade $95 \%$ of the gliadins (Loponen, Sontag-Strohm, Venäläinen, and Salovaara, 2007), leading to bread that is low in gliadins. An alternative approach is the use of enzyme extracts from a small stock of germinated seeds (particularly barley seeds). This has recently been suggested to be applicable to the large-scale production of flour with a reduced gliadin content (Stenman et al., 2010; Schwalb, Wieser, and Koehler, 2012).

\subsubsection{Sourdough fermentation and dough acidification}

Sourdough is the result of the activity of micro-organisms (Lactobacilli and yeast) naturally present in flour, becoming active when water is added. Lactobacillus ferments the flour/water mixture creating lactic acid, acidifying the mixture. This enhances the activity of propyl endopeptidase (PEP) enzymes produced by other micro-organisms to degrade gluten proteins (Hartmann, Koehler, and Wieser, 2006; Gänzle, Loponen, and Gobbetti, 2008; Loponen et al., 2009). Sourdough fermentation has been suggested as a way of enabling the manufacture of gluten-free or 'low-in-gluten' $(<100 \mathrm{ppm})$ wheat-based products through proteolytic gluten degradation (Loponen, 2006). Similarly, chemical acidification of conventional dough has been shown to activate PEP activity, resulting in increased prolamin degradation (Kanerva et al., 2011), although not as much as in traditional sourdough. However, artificially acidified dough may trigger more intestinal permeability (Di Cagno et al., 2004) and enhance nonenzymatic deamination of gluten peptides, which may render them more immunogenic (Arentz-Hansen et al., 2000).

Sourdough fermentation is a traditional baking process with a long history, particularly in Germany. The prevalence of CD in Germany (measured using a single antibody test) has been found to be remarkably low, $0.4 \%$ and $0.2 \%$ in women and men, respectively (Kratzer et al., 2013), confirming earlier data showing a $0.1-0.4 \%$ prevalence on the basis of anti-tTG and anti-endomysial antibody (EMA-IgA) tests (Mustalahti et al., 2010). Recent estimations of the celiac prevalence in Germany have increased to $0.8 \%$, especially in children and young adults up to 17 years old (Laass et al., 2015). This may reflect underdiagnosis in earlier studies. However, if sourdough indeed reduces the exposure to intact gluten epitopes, then the recent increase in $\mathrm{CD}$ prevalence in young people may reflect a change in the diet of German children towards white and yeast-based bread.

Recently, Greco et al. (2011) described a two-step hydrolysis including fungal proteases and Lactobacillus endo-peptidase activity, which resulted in a wheat flour-derived product with $<10 \mathrm{ppm}$ gluten. This product was found not to be harmful to CD patients (Greco et al., 2011). These observations are promising, but further research on the potential of sourdough products in a safe 'gluten-free' diet is needed, examining individual cases. Firstly, a strict definition on the type of sourdough is required, and the process of gluten degradation needs to be analysed in detail. Secondly, it needs to be determined whether large-scale consumption by the general population of well-defined sourdough products can indeed contribute to the reduction of the incidence and symptom severity of CD and NCWS. This will require large-scale epidemiological studies.

\subsubsection{Degradation of gluten using a peptidase}

Walter, Wieser, and Koehler (2014) showed that AN-PEP, an Aspergillus niger prolyl endopeptidase, can be used to degrade gluten in wheat bran to below $20 \mathrm{ppm}$. Such treated wheat bran could have a use in increasing the nutritional value of the gluten-free diet, e.g. by increasing soluble fibre content.

\subsubsection{Separation of gliadins from total gluten}

Extraction of HMW-glutenins from total gluten and substitution of the highly immunogenic wheat gliadins with, for instance, coeliac-safe oat avenins in order to maintain good baking quality (van den Broeck, Gilissen, Smulders, van der Meer, and Hamer, 2011), is a realistic option in foods aiming at a strongly reduced immunogenic gluten load. Nearly complete separation can be achieved at the lab scale (Bassi, Maningat, Chinnaswamy, Gray, and Nie, 1997; Gilissen et al., 2012; Lagrain, Brunnbauer, Rombouts, and Koehler, 2013). Industrial scaleup to economically and technologically viable levels appears to be more problematic, and would need further research. Alternatively, $\alpha$-gliadins, the most immunogenic gluten proteins, can be partially removed mechanically using roller-milling to remove the seed sub-aleurone layer, in which a large fraction of the $\alpha$-gliadins are deposited (van Herpen et al., 2008; Sutton, Simmons, Cummack, and Roberts, 2015).

\subsubsection{Reduction of the use of vital gluten}

Vital (or purified) wheat gluten is a major side-product of wheat starch production. Starch is used to make native and modified starch, glucose syrup, maltodextrins, and liquid and crystalline polyols, with wide applications in the food industry. Wheat starch is also used for the production of alcohol, including bioethanol. Since wheat starch is economically more important than flour for bakery purposes, vital gluten production (as side-product of starch isolation) is large, and its cost relatively low.

Vital gluten is increasingly applied as a protein additive in food products to improve technological characteristics. In bread and bakery products vital gluten is added to maintain high loaf volumes, but most of its use is in the form of a 'hidden' ingredient, often not labelled, in a large number of processed food products. This may have contributed to the increase in total gluten consumption: between 1977 and 2007, gluten intake in the western world has tripled (Kasarda, 2013). Currently, a 'back to basics' philosophy in modern bakeries in The Netherlands has led to 'clean label' strategies, and avoidance (or strong reduction) of bread quality-improving ingredients such as enzymes and vital gluten in artisanal and industrial whole grain breads. There is, however, no indication of a reduction in the use of vital gluten in other food production sectors.

\section{Wheat breeding strategies for products with low gluten immunogenicity ('coeliac-safe wheat')}

An alternative strategy for the production of gluten-free wheatbased food is to develop wheat varieties with fewer or no immunogenic CD epitopes (Fig. 1c) (Gilissen, van der Meer, and Smulders, 2008; Shewry and Tatham, 2016). To be able to generate such varieties, one must be aware of the complexity of wheat genome and the structure of gene families coding for gliadin immunogenic CD epitopes.

\subsection{Wheat breeding background: genomics, gluten gene families and gliadin protein epitopes}

The ancestor of all wild and cultivated wheat species was a diploid grass $(2 n=14)$, which evolved into several diploid species (e.g. Goncharov, 2011; Goryunova et al., 2012). Natural allopolyploidisation occurred through hybridisation between the diploid species Triticum urartu (AA genome) and Aegilops speltoides (BB or SS) followed by chromosome doubling, resulting in tetraploid emmer wheat, T. turgidum spp. dicoccoides (AABB). Much later, tetraploid emmer hybridized with goat grass, Aegilops tauschii (DD), followed by chromosome doubling, resulting in hexaploid bread wheat, Triticum aestivum (AABBDD) (Gupta, Mir, Mohan, and Kumar, 2008). The latter allopolyploidisation took place in agricultural fields early after the start of cultivation of 
emmer wheat. Bread wheat does not occur in nature.

The $\alpha$-gliadins are encoded by a large gene family of perhaps 150 genes, located on the short arms of the group 6 chromosomes (6AS, 6BS and 6DS) (Shewry, Halford, and Lafiandra, 2003). The $\gamma$-gliadins, $\omega$ gliadins and LMW-glutenins are encoded by gene families located on the short arms of the group 1 chromosomes (1AS, 1BS and 1DS), while the HMW-glutenins are encoded by gene families located on 1AL, 1BL and 1DL.

The presence of the $\mathrm{D}$ genome in hexaploid T. aestivum provides additional gluten proteins, which considerably improve its bread baking properties compared to tetraploid wheat, particularly HMWglutenin subunits (Payne, Jackson, and Holt, 1984). However, the D genome also encodes for gliadins that have been reported as highly immunogenic.

CD epitopes are 9 amino acids in length, and form the peptide fragment that fits into the T cell HLA-DQ2 and HLA-DQ8 epitopepresenting receptor grooves. The list of well-defined $\mathrm{CD}$ epitopes (Sollid, Qiao, Anderson, et al., 2012) comprises: twenty-four DQ2 epitopes and seven DQ8 epitopes, including six epitopes present in $\alpha$ gliadins and eleven in $\gamma$-gliadins, complemented by two $\omega$-gliadin epitopes, three LMW-glutenin, and two HMW-glutenin epitopes. The HLA-DQ8 epitopes play a minor role in the development of CD, since over $90 \%$ of CD patients are HLA-DQ2 positive and react to $\alpha$-gliadins (Koning, 2012, 2015). The HLA-DQ/gliadin peptide/T cell interactions have been characterised extremely well. The positions that are crucial for immune reactivity of $\alpha$-gliadins, identified by T cell tests (e.g., Mitea et al., 2010), correspond exactly with the amino acid residues that form the crucial hydrogen bridges that connect HLA-DQ2 (Petersen et al., 2014 ) to the T cell receptor, a connection which, if sufficiently stable, triggers the immune reaction in humans. The structure of the HLADQ8/gliadin peptide/T cell interaction has also been characterised in detail (Petersen et al., 2016).

At the genomic level, the occurrence of CD epitopes varies between gliadin genes (each locus comprising multiple gene copies), between homoeologous wheat chromosomes (A, B, D), and among wheat varieties and species (Spaenij-Dekking et al., 2005; Molberg et al., 2005; van Herpen et al., 2006; Salentijn et al., 2009; Salentijn et al., 2012; van den Broeck, de Jong, et al., 2010; van den Broeck, Hongbing, et al., 2010; van den Broeck et al., 2015). The $\alpha$-gliadins from the D genome contribute most $\mathrm{CD}$ epitopes, while those from the B genome contribute the least (van Herpen et al., 2006; Salentijn et al., 2009). For $\gamma$-gliadins, the highest number of $\mathrm{CD}$ epitopes has also been found in genes present on the D genome (Salentijn et al., 2009; Salentijn et al., 2013). While less sequence information is available for $\omega$-gliadins, their involvement in CD immunogenicity has been recently recognized from cross-reactivity of $\mathrm{T}$ cells with rye and barley epitopes (Tye-Din et al., 2010).

We will first discuss research approaches aimed at identifying naturally occurring variation within gliadin gene sequences and loci. This genetic variation can be used in conventional breeding and forward genetics approaches, by introgression into new wheat varieties. However, there is limited prospect for success, as multiple gliadin loci occur in the polyploid wheat genome, and glutenins and gliadins are encoded by large gene families, so multiple genes need to be screened. Many of the genes are closely linked in the genome, which limits the frequency of recombination, making selection of appropriate variation through a breeding approach difficult. Therefore, the use of reverse genetics approaches, such as random mutagenesis and transgenic methods (such as gene silencing) or gene editing are considered attractive options to create wheat varieties with reduced gluten immunogenicity. We will discuss such approaches later in this review.

When these approaches lead to wheat varieties with fewer gliadin proteins, this may affect baking quality. The effect should be compensated for, and one approach is the addition of celiac-safe proteins that perform the same function in the GMP (Gilissen et al., 2012, Smulders et al., 2015), as was demonstrated for oat avenins added to flour of wheat deletion lines lacking certain groups of gliadins (van den Broeck et al., 2009).

\subsection{Selection of low CD-toxic wheat accessions and varieties}

Genebanks around the world contain modern and old varieties of hexaploid and tetraploid wheat varieties, as well as landraces (locally adapted wheat accessions), wild emmer (Triticum dicoccoides) and wild diploid species that are related to the ancestors of cultivated wheat (crop wild relatives). These collections are a useful source of wheat germplasm for analysing the relationships between individual gluten genes or proteins, the occurrence of epitope variants, and the resulting CD immunogenicity.

While there is large variation in the presence of intact CD epitopes among individual $\alpha$-gliadin genes, all wheat varieties or accessions express multiple gliadins (Salentijn et al., 2013), which reduces the variation detected between varieties by immunogenic screening approaches. Indeed, screening with monoclonal antibodies (mAbs) for two $\mathrm{CD}$ epitopes revealed limited genetic variation in gliadins immunogenicity among modern wheat varieties (van den Broeck, de Jong, et al., 2010). Some older hexaploid wheat varieties were identified with somewhat lower mAb response, as well as two lines derived from a heterogeneous tetraploid durum wheat landrace (van den Broeck, Hongbing, et al., 2010). In addition, analysis of nine landraces of farro wheat (T. turgidum ssp. dicoccum) revealed three landraces that caused negligible proliferation of T-cell lines from CD patients, whereas the other landraces studied showed intermediate to very high responses (Vincentini et al., 2009).

Diploid einkorn wheat (T. monococcum, A genome) has good nutritional characteristics and bread making quality. Food products made from the variety 'Monlis' have been shown to be tolerated by CD patients, revealing similar absence of CD toxicity-related symptoms as found for rice (Zanini et al., 2013). New combinations of gluten genes can be made by crossing and selection at the diploid level. Although this is a time-consuming procedure, the increasing incidence of $\mathrm{CD}$ in recent decades would justify selection for reduced CD epitopes levels as a novel quality trait for wheat breeding (van den Broeck et al., 2011).

The utility of screening wheat germplasm using epitope-specific mAbs is, however, limited. The specificity of mAbs is not exactly the same as that of the $\mathrm{T}$ cell epitopes, as mAbs only recognise peptide sequences of 4-6 amino acids in length, which is substantially shorter than the 9 amino acid $\mathrm{T}$ cell epitopes that cause CD (Londono et al., 2013). Therefore, the identification of wheat genotypes with reduced $\mathrm{CD}$ toxicity using mAbs should be regarded as a preliminary screen, to be followed by screening of selected lines with more accurate methods.

Salentijn et al. (2013) have examined the CD immunogenic potential of tetraploid durum wheat by deep sequencing of $\alpha$-gliadin transcripts, including the sequences coding for both the N-terminal domain and the repetitive domain, where the $\mathrm{CD}$ epitopes occur, from developing grains. They found differences among varieties, but no variety was identified as safe for $\mathrm{CD}$ patients. Dubois, Bertin, and Mingeot (2016) screened spelt lines by sequencing $\alpha$-gliadin genes expressed in the developing grains. They saw no clear separation in the occurrence of epitopes between spelt and bread wheat accessions, although some spelt lines expressed more B-genome $\alpha$-gliadins, which contain fewer epitopes.

A direct approach would be to use quantitative proteomics to identify the gliadins in mature grains, as this would determine the exact amino acid sequence and the quantity of the proteins produced during grain development. However, this is complicated by the diversity of gluten genes in any single wheat variety, and the relative insensitivity of these proteins to the proteolysis step necessary for analysis. A method has recently been developed that enables identification and quantification of specific CD-epitopes in chymotryptic gluten digests (Dubois et al., 2016). 


\subsection{Reconstituting hexaploid bread wheat: synthetic hexaploids}

Overall, the genetic variation of the D genome in hexaploid bread wheat is much lower than the genetic variation present in the A and B genomes. This is consistent with the theory that the hybridisation that led to hexaploid bread wheat resulted in a strong genetic bottleneck (Reif et al., 2005; Jones et al., 2013). Indeed, several studies have found high levels of genetic diversity among wild Ae. tauschii accessions (Wang et al., 2013; Jones et al., 2013). In order to introduce additional genetic diversity into bread wheat, programmes that recreate the hybridisation process to generate 'synthetic hexaploid wheat' (SHW) have been undertaken at various institutes around the world, including the International Maize and Wheat Improvement Centre (CIMMYT, Mexico), NIAB (UK), and the Commonwealth Scientific and Industrial Research Organisation (CSIRO, Australia). The process involves hybridising T. turgidum spp. durum with Ae. tauschii, followed by rescue of the triploid embryo, and subsequent chromosome doubling using colchicine to generate hexaploid individuals. Careful selection of diverse Ae. tauschii donors can result in SHW accessions that maximise the D genome variation captured, and so increase the potential benefit of SHW in wheat breeding programmes. Ae. tauschii accessions which are low in CD-toxic gliadins could for instance be hybridized with two tetraploid durum wheat landraces that have been shown to possess a relatively low mAb response (van den Broeck, Hongbing, et al., 2010), to generate a low gluten immunogenic SHW. These SHWs could then be used in pre-breeding programmes for crossing with commercial varieties, combining screening for low gluten immunogenic progeny with the presence of competitive agronomic characters.

\subsection{Mutation breeding}

Mutation breeding is based on the random induction of genomewide mutations, followed by selection of plants carrying mutations in the gene(s) of interest; products of mutation breeding can be released on the market without regulation. The type and frequency of mutations obtained in classical mutagenesis programmes depends on the method used (chemical or ionizing radiation), the type and concentration of mutagen, and the duration of the treatment, which are adjusted on a case by case basis. Polyploid crops in general tolerate higher mutation loads than diploid crops (Shu, Forster, and Nakagawa, 2011; Oladosu et al., 2016). This is certainly necessary for gliadin mutagenesis in wheat: stacking mutations in multiple gliadin genes into a single plant through crossing is very challenging, due to the number of gliadin genes and their close physical linkage, so this strategy can only be effective if the starting lines already contain many mutated gliadin genes or many gliadins have been deleted from them.

\subsubsection{EMS}

Ethyl methane sulfonate (EMS) is a chemical mutation approach that primarily results in transitions of $\mathrm{G} / \mathrm{C}$ to $\mathrm{A} / \mathrm{T}$ nucleotides in the DNA. In the context of $\alpha$-gliadin and $\gamma$-gliadin genes, EMS treatment may result in mis-sense mutations within epitopes, which could disrupt binding to the Antigen Presenting Cells, or non-sense mutations upstream of the epitopes which truncate the protein or prevent its translation. EMS mutations are detected using an approach termed Targeting Local Lesions IN Genomes (TILLING). Detection of induced mutations originally relied on enzyme-mediated cleavage of mismatched nucleotides (McCallum, Comai, Greene, and Henikoff, 2000), but is now commonly done by DNA sequencing of either the complete genome or a subset of the genome, either produced with restriction enzymes or using approaches such as exome capture. Acevedo-Garcia et al. (2017) used TILLING to identify missense mutations in each of the three wheat Mildew Locus O (TaMLO) homoeologues, which were subsequently stacked to produce plants with enhanced, yet incomplete, resistance towards powdery mildew (Blumeria graminis $f$. sp. tritici (Bgt)).
A straightforward screening system for EMS TILLING populations has been constructed in tetraploid ( $T$. turgidum cv. Kronos) and hexaploid (T. aestivum cv. Cadenza) wheat. Both TILLING populations have recently been sequenced using exome capture (Krasileva et al., 2017), allowing identification of TILLING mutants in target genes via DNA sequence searches of online databases (www.wheat-tilling.com/). Gluten gene mutants can be identified bioinformatically in these populations, but in practice few mutated gliadin genes have been found. The high copy number and sequence similarity make it difficult to correctly assemble gliadin sequences. As a consequence, assembly of sequence reads from a mutated population runs the risk of combining reads with point mutations from multiple genes into single sequence assemblies. If filtered out, this could lead to an artificially low mutation frequency, but if not filtered, it could result in an over-estimation of the average number of mutations per gene. The use of Pacific Bioscience Circular Consensus Sequencing (PacBio CCS), which produces longer sequence reads, may solve some assembly issues. However, the resulting sequence data would likely still need to be combined with more accurate short read sequencing approaches (e.g. Illumina) to compensate for the relatively high PacBio sequencing error rate.

\subsubsection{Gamma irradiation}

Gamma $(\gamma)$-irradiation produces reactive oxygen species (ROS) that cause DNA oxidative damage or DNA single/double strand breaks. Double strand breaks are repaired by the cell's non-homologous end joining (NHEJ) mechanism, which is a relatively error-prone process. Most errors lead to small deletions, although base-pair substitutions, inversions, and small insertions also may be found (Cockram, Mackay, and O'Sullivan, 2007; Morita et al., 2009). Gamma irradiation therefore has the potential to mutate epitopes, remove whole gliadin genes, or even delete multiple gliadin genes.

In barley, $\gamma$-irradiated accession Ris $\emptyset 56$ (lacking B-hordeins), Ris $\varnothing$ 1508 (lacking C-hordeins) and R118 (an Ethiopian derived line which lacks D-hordeins) have been intercrossed to produce an Ultra Low Gluten variety (ULG 2.0) with a reduction of hordein (gluten) content below 5 ppm, thus allowing it to be classified as 'gluten-free' (Tanner, Blundell, Colgrave, and Howitt, 2016). Subsequent crossing and selection with commercial varieties resulted in a variety with good malting and brewing characteristics (now marketed as 'Kebari'). Interestingly, in several countries the products made with this variety cannot legally be marketed as gluten-free, solely because it contains barley.

In wheat a strategy to introduce similar resources into commercial breeding programmes could be based on screening $\gamma$-irradiated hexaploid wheat populations, such as that created in the UK from the commercial cultivar Paragon. We are currently screening these lines for changes in their gluten pattern on acid PAGE protein gels (Cooke, 1995), prior to further characterisation of a subset of lines using approaches such as RNA-seq, qPCR, and/or proteomics.

\subsubsection{Deletion lines}

Wheat deletion lines are available in which whole chromosomes, or parts of chromosomes, have been deleted by crossing monosomic with tetrasomic lines, or by introgression of alien addition or translocation lines into cv. 'Chinese Spring' to induce deletions (Endo and Gill, 1996). A set of these hexaploid wheat cv. 'Chinese Spring' deletion lines has been used to test the effects of individual deletions on the reduction of $\mathrm{CD}$ epitopes and on technological properties. A deletion line missing the short arm of chromosome 6D (6DS) in which the 6D $\alpha$-gliadin locus had been deleted, was found to have strongly decreased mAb responses against Glia- $\alpha 1$ and Glia- $\alpha 3$ epitopes (van den Broeck et al., 2009). The absence of these $\alpha$-gliadin proteins also led to a significant change in dough mixing properties and dough rheology, as the dough became stiffer and less elastic. In contrast, the deletion of the $\omega$-gliadins, $\gamma$ gliadins and LMW-glutenin subunits on chromosome 1DS removed some epitopes, but the technological properties were retained (van den Broeck et al., 2009). 


\subsection{Transgenic approaches to reduce CD toxicity}

Until recently, wheat was considered a challenging crop for genetic transformation; particle bombardment was routinely used for delivery of gene constructs, despite its many drawbacks in the quality of plants generated, which included multiple insertions with complex rearrangements. Furthermore, only a limited range of germplasm could be utilised. The development of supervirulent Agrobacterium tumefaciens strains (Wu, Doherty, and Jones, 2008), plus changes to media components and the introduction of new techniques (Wu, Sparks, Amoah, and Jones, 2003; Risacher, Craze, Bowden, Paul, and Barsby, 2009) improved efficiency. However, the major breakthrough was made by Ishida, Tsunashima, Hiei, and Komari (2014), using the US soft white wheat, Fielder. This new technology is implemented at NIAB and has been used to both extend the range of UK spring and winter germplasm which can be transformed, and to support a high throughput wheat transformation platform.

\subsubsection{Gene silencing using RNA interference}

RNA interference (RNAi) is a conserved biological process initially identified as a plant defence mechanism, in which a viral doublestranded RNA (dsRNA) is cleaved, silencing viral gene expression and inhibiting further replication (Ratcliff, Harrison, and Baulcombe, 1997). It has since been demonstrated that genetic transformation of plants with a construct encoding a dsRNA molecule similar to an endogenous plant single-stranded mRNA, triggers silencing of that specific plant gene (Waterhouse and Helliwell, 2003).

Two research groups have successfully silenced gliadin expression using RNAi. Becker et al. (2012) silenced $\alpha$-gliadins, eliminating 20 different storage proteins from the grain, whereas Gil-Humanes, Pistón, Tollefsen, Sollid, and Barro (2010) down-regulated gliadins from all groups in bread wheat, with an average reduction of $92.2 \%$ in the R5 mAb assay. T cell tests demonstrated a 10-100-fold reduction in DQ2 and DQ8 epitopes from $\alpha$-gliadins, $\gamma$-gliadins and $\omega$-gliadins. Indeed, total gluten extracts of three transgenic wheat lines did not to stimulate $\mathrm{T}$ cell clones. Down-regulation of $\gamma$-gliadins resulted in an increase of other gluten proteins in the grains (Gil-Humanes et al., 2010), but little or no effect was found on dough strength or gluten and starch properties (Pistón, Gil-Humanes, Rodríguez-Quijano, and Barro, 2011; Gil-Humanes, Pistón, Giménez, Martín, and Barro, 2012; Gil-Humanes et al., 2014).

RNAi has also been used to suppress the DEMETER (DME) homoeologues in wheat (Wen et al., 2012). The DME gene encodes a 5methylcytosine DNA glycosidase that demethylates the promotor regions of gliadins and LMW-glutenins in the wheat endosperm. This demethylation is essential for activation of the genes during endosperm development. DME RNAi transgenic plants showed a high degree of $D M E$ transcript suppression, resulting in $>75 \%$ reduction in the amount of immunogenic prolamins.

Providing their agronomic properties and yields are acceptable, such RNAi wheat lines may become candidates for the production of wheat-based products for 'gluten-free' or 'low-in-gluten' diets. However, it should be noted that these strategies require a stable integration of the RNAi cassette into the genome, thus resulting in a genetically modified (GM) plant. It is therefore subject to relevant national and international GM regulations, with the accompanying long, expensive, and uncertain procedure for market approval.

\subsubsection{Targeted mutagenesis to generate small indels and to delete genes}

In contrast to mutation breeding, genome (gene) editing approaches aim to induce mutations only within specific targets. These methods include Meganucleases, Zincfinger nucleases, TALENs and CRISPRCas9. The regulatory status of plants and plant products derived from gene editing is currently unclear in the European Union (Sprink, Eriksson, Schiemann, and Hartung, 2016). The current method of choice is CRISPR-Cas9 due to its ease of use (e.g., Schaart, van de
Wiel, Lotz, and Smulders, 2016). The CRISPR-Cas9 system was originally described as a bacterial defence mechanism against viral infections (Barrangou et al., 2007) and has since been customised to induce mutations and deletions at specific locations within a target gene in animals and plants (Belhaj et al., 2013; Zhou, Liu, Weeks, Spalding, and Yang, 2014; Schaart et al., 2016). Mutations can be induced by introducing a guide RNA (gRNA) complementary to the gene of interest, plus an expression cassette to express the Cas9 endonuclease protein. The 20-mer gRNA directs the Cas9 nuclease to the target site within the gene of interest, where the nuclease generates a double strand DNA break, three bases upstream of a specific protospacer adjacent motif (PAM). In plants, repair by NHEJ can result in insertion/deletions (indels) and other mutations, that can result in beneficial phenotypes (Schaart et al., 2016; van de Wiel et al., 2017).

CRISPR-Cas9 and other site-directed nucleases have been successfully used to target homeologous genes in diploid and polyploid crops (Brooks, Nekrasov, Lippman, and van Eck, 2014; Lawrenson et al., 2015). In potato, the four copies of Granule-bound starch synthase (GBSS) have been simultaneously modified to alter starch composition in tetraploid potato (Andersson et al., 2017). In bread wheat, the TALEN system was used to simultaneously mutate the three homoeologs of an TaMLO gene (Wang et al., 2014). Using a Cas9/guide ribonucleoprotein complex in plant callus, protoplasts and immature embryos, homeologous genes were successfully edited in hexaploid and durum wheat (Zhang et al., 2016; Liang et al., 2017). In this system no foreign DNA is added to the plant cell, so plants developed in this manner might not be regulated as GM, as was recently propositioned by the U.S. Department of Agriculture's (USDA) Animal and Plant Health Inspection Service (APHIS) in its proposed revision of regulations (USDA, 2017).

With these examples, it should also be feasible to modify and/or delete gliadin genes from hexaploid wheat. Such experiments are ongoing at NIAB and elsewhere. In theory, several types of mutations could be generated in the gliadin genes. Small indels, within or upstream of the epitope region, can generate premature stop codons resulting in truncated proteins that lack $\mathrm{CD}$ epitopes or within modified epitopes which are no longer immunogenic. Moreover, genes of the $\alpha$-, $\gamma$ - and $\omega$ - gliadin families are each grouped at single loci on the short arms of the group 6 and 1 chromosomes, respectively. The $\alpha$-gliadin Gli-2 loci contains $\alpha$-gliadin interspersed with retrotransposons (Gu et al., 2004). The $\gamma$-gliadin locus also includes other prolamin and nonprolamin genes (Gao et al., 2007). Cas9-mediated double strand breaks generated simultaneously in at least two gliadin genes on the same chromosome may result in a deletion of the intervening genes. Similarly, multiplexing gRNAs to target different sites within one gliadin gene could, together with a high mutation rate, delete only the immunogenic epitopes from the gliadin protein.

Following wheat transformation with the gliadin gene editing construct, T1 seed could be analysed by Acid-PAGE separation of storage proteins, allowing rapid identification of plants with modified gliadin profiles. Lines of interest could then be further analysed using methods such as deep sequencing of the genome, digital drop real-time PCR to determine gliadin copy number, and RNA-seq of developing grains to determine gene expression profiles. Jouanin et al. (in preparation) are currently using a process termed 'Gluten genes Enrichment and Sequencing' (GlutEnSeq), a protocol based on REnSeq methods (Jupe et al., 2013). This approach uses exome capture to enrich for gluten gene genomic DNA from lines of interest for targeted re-sequencing, preferably using a long read technology such as PacBio. Proteomics methods such as LC-QTOF-MSMS could be used to generate information on the composition of the gliadins produced in mutant lines, to quantify epitope levels, and to determine the occurrence of amino acid changes in epitope-harbouring peptide fragments. 


\section{Prospects for the low gluten immunogenicity strategies}

The food processing and wheat breeding strategies described represent two major routes for the development of cereal products with low gluten immunogenicity. Gluten-free products, made without wheat, barley or rye, are now increasingly found on grocery store shelves. However, these products typically require the inclusion of numerous additives, resulting in products that are often less healthy than gluten-based equivalents. To overcome this issue, other strategies have to be deployed.

Malting may be one of the most applicable methods for large-scale preparation of products with low gluten immunogenicity in the food processing industry, and it can even enhance sourdough fermentation when the malting process is not fully stopped. Similarly, sourdough is a traditional method used to increase loaf volume for bread baking which is possible to implement at industrial scale. Sourdough can also be combined with malting for further reduction of gluten immunogenicity. However, in addition to being more time consuming, sourdough has a taste that may not be widely accepted by consumers.

While the separation of gliadins from glutenins, followed by substitution of gliadins for non-immunogenic oat avenins, is possible at a laboratory scale, large-scale implementation could be challenging and would require considerable infrastructure. From another perspective, the labelling and reduction in the use of vital gluten as an additive, used as source of protein to improve food structure, is a simple approach that would improve the healthiness of gluten-sensitive patients. Unlike GM breeding techniques, most of the candidate food processing techniques for making low gluten-immunogenic products are already implemented, and do not arouse ethical and political issues.

From a wheat breeding perspective, very few polyploid wheat accessions show low gliadin immunogenicity, and those that do lack the agronomic characteristics required for commercial varieties. Introgression of the multiple low immunogenic gliadin loci involved into commercial varieties would be a complex undertaking. Since the expected result would only be a low-immunogenic line, not a CD-safe wheat, it is not anticipated to be a likely near-term target in wheat breeding.

Mutation breeding represents an attractive option to create wheat with low gluten immunogenicity. EMS TILLING on members of large gene families is challenging. Again multiple mutations are necessary, but if these occur in multiple plants then a programme of backcrossing followed by recurrent self-pollination would be required to remove background mutations, while retaining as many homozygous gliadin mutations as possible. However, as the gliadins are closely linked on chromosome 1 and 6 , the recombination events required to combine all mutations in a single genetic background might be very rare. Induced mutations using $\gamma$-irradiation would be a more tractable approach, since multiple gliadin genes may be removed in single deletion events. This approach has been successfully undertaken in the diploid crop barley, where inter-crossing $\gamma$-irradiated lines, each missing a different prolamin gene family, generated an Ultra Low Gluten line that was successfully crossed with commercial varieties (Tanner et al., 2016), leading to a commercial variety with $<20 \mathrm{ppm}$ gluten. In theory, this line could be used for breeding more low-gluten barley varieties, although it would represent a major bottleneck for genetic diversity around these deletions. The variety also comes with a yield penalty. It is not expected that this line will be used by other breeders to generate low-gluten barley in the short term (Tanner, pers. comm.). However, the case for wheat may be stronger, as CD patients encounter wheat gluten in many food products, but can easily avoid barley by drinking only gluten-free beer.

The use of RNAi in wheat has been shown to be very efficient in decreasing the amount of gliadins expressed in the grain, without greatly altering dough properties. Nonetheless, the RNAi construct must be retained in the plant genome, resulting in a GM plant. Multiple factors restrict the commercial feasibility of using GM crops, including the costs of the regulatory process in those countries that allow GM crops (Laursen, 2016). However, this may not be the case with CRISPRCas9 technology, as after having generated inheritable mutations in target genes, the T-DNA can be crossed out. Whether the resulting products, which do not contain foreign DNA, will be regulated as GM plants, is under debate (Sprink et al., 2016). In some countries, processbased regulation may define them as GM, whereas other countries with a more product-based approach may consider them to be identical to plants produced by conventional or mutation breeding. The European Food Safety Authority (EFSA) GMO panel (2015) considered the use of site-directed nucleases for inducing small deletions or insertions at a precisely defined location in the genome $(S D N-1)$ as a form of mutagenesis. Acceptance by consumers may also be an issue (Ishii and Araki, 2016) but acceptance of products that are tailored to the needs of specific groups of consumers (e.g., hypoallergenic fruits, nuts etc.) is probably much higher than that of products tailored to the needs of producers or the general public (Schenk et al., 2008; Schenk et al., 2011; Kronberger, Wagner, and Nagata, 2014).

In the future, low gluten immunogenicity may become one of many traits included in commercial breeding programmes. Achieving low gluten-immunogenic wheat, and ultimately food products, will require a great deal of effort and is likely to require changes in industrial grain and food processing processes. Despite these challenges, the importance of wheat (and other gluten-containing immunogenic grains) in the human diet, along with the increasing worldwide incidence of immunogenic diseases such as $\mathrm{CD}$, means that it is imperative that these challenges are now addressed.

Depicted are simplified food supply chains comprising of two steps, plant breeding and food processing, leading to the final food product. Three variants, a), b) and c), of this food supply chain can be envisaged, depending on the step at which efforts are made to generate gluten-free or coeliac-safe(r) products and whether the process includes wheat ingredients or not. These three variants are presented here in the same order as described in the paper. a) Gluten-free products are generated using substitutions for wheat to avoid the presence of its immunogenic gluten fraction. b) Coeliac-safer of coeliac-safe products could be made at the food-processing step by processing wheat grains to decrease their immunogenic gluten fraction before proceeding to processing of the final product. c) Coeliac-safer or coeliac-safe products could be made based on plant breeding of wheat varieties with reduced immunogenic gluten fraction, used in a standard grain processing and final food product processing. Note that b) and c) can complement each other to achieve a further reduction of gluten immunogenicity.

\section{Acknowledgements}

Writing this study was partially funded by the EFRO project 'Nieuwe detectiemethoden voor coeliakie en coeliakie-inducerende gluten in voeding' (2011-018974), FP7 EID Max-imising the potential of CROP researchers (Max-CROP, grant no. 607178), and the Global One Health project. It does not necessarily reflect the views of the European Commission and in no way anticipates the Commission's future policy in this area. This study is linked to preparations for Well on Wheat (WoW), an international research project under the umbrella of Health Grain Forum and ICC-Vienna, addressing the effects of wheat composition and processing on food compositional changes and on related effects on gastrointestinal function and symptoms in humans.

\section{References}

Acevedo-Garcia, J., Spencer, D., Thieron, H., Reinstädler, A., Hammond-Kosack, K., Phillips, A. L., \& Panstruga, R. (2017). mlo-Based powdery mildew resistance in hexaploid bread wheat generated by a non-transgenic TILLING approach. Plant Biotechnology Journal, 15, 367-378. http://dx.doi.org/10.1111/pbi.12631.

Andersson, M., Turesson, H., Nicolia, A., Fält, A. S., Samuelsson, M. \& Hofvander, P. (2017). Efficient targeted multiallelic mutagenesis in tetraploid potato (Solanum tuberosum) by transient CRISPR-Cas9 expression in protoplasts. Plant Cell Reports, 36 , 
117-128, http://dx.doi.org/10.1007/s00299-016-2062-3.

Arentz-Hansen, H., Körner, R., Molberg, Ø., Quarsten, H., Vader, W., Kooy, Y. M., .. McAdam, S. N. (2000). The intestinal T cell response to $\alpha$-gliadin in adult celiac disease is focused on a single deamidated glutamine targeted by tissue transglutaminase. Journal of Experimental Medicine, 191, 603-612.

Atchison, J., Head, L., \& Gates, A. (2010). Wheat as food, wheat as industrial substance; comparative geographies of transformation and mobility. Geoforum, 41, 236-246.

Barrangou, R., Fremaux, C., Deveau, H., Richards, M., Boyaval, P., Moineau, S., ... Horvath, P. (2007). CRISPR provides acquired resistance against viruses in prokaryotes. Science, 315, 1709-1712.

Bassi, S., Maningat, C. C., Chinnaswamy, R., Gray, D. R., \& Nie, L. (1997). Midwest grain products. Alcohol-free wet extraction of gluten dough into gliadin and glutenin. 610, (pp. 277-). United States Patent o 5.

Becker, D., Wieser, H., Koehler, P., Folck, A., Mühling, K. H., \& Zörb, C. (2012). Protein composition and techno-functional properties of transgenic wheat with reduced alpha-gliadin content obtained by RNA interference. Journal of Applied Botany and Food Quality, 85, 23-33.

Belhaj, K., Chaparro-Garcia, A., Kamoun, S., \& Nekrasov, V. (2013). Plant genome editing made easy: Targeted mutagenesis in model and crop plants using the CRISPR/Cas system. Plant Methods, 9, 39.

Belz, M. C. E. (2016). Reduction of salt in yeasted wheat bread: Impact on bread quality and solutions using sourdough fermented by functional lactic acid bacteria strains. Chapter 5University College Cork Thesis.

Bigiarini, L., Pieri, N., Grilli, I., Galleschi, L., Capocchi, A., \& Fontanini, D. (1995). Hydrolysis of gliadin during germination of wheat seeds. Journal of Plant Physiology, $147,161-167$.

Brooks, C., Nekrasov, V., Lippman, Z. B., \& van Eck, J. (2014). Efficient gene editing in tomato in the first generation using the clustered regularly interspaced short palindromic repeats/CRISPR-associated9 system. Plant Physiology, 166, 1292-1297.

Caponio, F., Summo, C., Clodoveo, M. L., \& Pasqualone, A. (2008). Evaluation of the nutritional quality of the lipid fraction of gluten-free biscuits. European Food Research and Technology, 227, 135-139.

Capriles, V. D., \& Arêas, J. A. G. (2014). Novel approaches in gluten-free breadmaking: Interface between food science, nutrition, and health. Comprehensive Reviews in Food Science and Food Safety, 13, 871-890.

Catassi, C. (2015). Gluten sensitivity. Annals of Nutrition \& Metabolism, 67(Suppl. 2), $16-26$.

Catassi, C., Gatti, S., \& Fasano, A. (2014). The new epidemiology of celiac disease. Journal of Pediatric Gastroenterology and Nutrition, 59(Suppl. 1), S7-S9. http://dx.doi.org/10. 1097/01.mpg.0000450393.23156.59.

Cockram, J., Mackay, I. J., \& O'Sullivan, D. M. (2007). The role of double-stranded break repair in the creation of phenotypic diversity at cereal VRN1 loci. Genetics, 177, 1-5.

Cooke, R. J. (1995). Gel electrophoresis for the identification of plant varieties. Journal of Chromatography A, 698, 281-299.

Di Cagno, R., De Angelis, M., Auricchio, S., Greco, L., Clarke, C., De Vincenzi, M., ... Minervini, F. (2004). Sourdough bread made from wheat and nontoxic flours and started with selected lactobacilli is tolerated in celiac sprue patients. Applied and Environmental Microbiology, 70, 1088-1096.

Dubois, B., Bertin, P., \& Mingeot, D. (2016). Molecular diversity of $\alpha$-gliadin expressed genes in genetically contrasted spelt (Triticum aestivum ssp. spelta) accessions and comparison with bread wheat (T. aestivum ssp. aestivum) and related diploid Triticum and Aegilops species. Molecular Breeding, 36, 152.

EFSA GMO UNIT (2015). EFSA response to DG SANTE request to provide technical assistance on issues related to the legal analysis of new plant breeding techniques. Mandate Number: M-2015-01834. http://registerofquestions.efsa.europa.eu/roqFrontend/ ListOfQuestionsNoLogin?1.

Endo, T. R., \& Gill, B. S. (1996). The deletion stocks of common wheat. Journal of Heredity, $87,295-307$.

Fasano, A. (2006). Systemic autoimmune disorders in celiac disease. Current Opinion in Gastroenterology, 22, 674-679.

Fasano, A. (2009). Surprises from celiac disease. Scientific American, August 2009 (pp 32-39).

Gänzle, M. G., Loponen, J., \& Gobbetti, M. (2008). Proteolysis in sourdough fermentations: Mechanisms and potential for improved bread quality. Trends in Food Science \& Technology, 19, 513-521.

Gao, S., Gu, Y. Q., Wu, J., Coleman-Derr, D., Huo, N., Crossman, C., ... Kong, X. (2007). Rapid evolution and complex structural organization in genomic regions harboring multiple prolamin genes in the polyploid wheat genome. Plant Molecular Biology, 65, 189-203.

Gil-Humanes, J., Pistón, F., Altamirano-Fortoul, R., Real, A, Comino, I., Sousa, C., Barro, F. (2014). Reduced-gliadin wheat bread: An alternative to the gluten-free diet for consumers suffering gluten-related pathologies. PloS One, 9e90898.

Gil-Humanes, J., Pistón, F., Giménez, M. J., Martín, A., \& Barro, F. (2012). The introgression of RNAi silencing of gamma-gliadins into commercial lines of bread wheat changes the mixing and technological properties of the dough. PloS One, $7 \mathrm{e} 45937$.

Gil-Humanes, J., Pistón, F., Tollefsen, S., Sollid, L. M., \& Barro, F. (2010). Effective shutdown in the expression of celiac disease-related wheat gliadin T-cell epitopes by RNA interference. Proceedings of the National Academy of Sciences of the United States of America, 107, 17023-17028.

Gilissen, L. J. W. J., van den Broeck, H. C., Londono, D. M., Salentijn, E. M. J., Koning, F. van der Meer, I. M., \& Smulders, M. J. M. (2012). Food-related strategies towards reduction of gluten intolerance and gluten sensitivity. In P. Koehler (Ed.), Proceedings of the 25th Meeting Working Group on Prolamin Analysis and Toxicity (pp. 29-35).

Gilissen, L. J. W. J., van der Meer, I. M., \& Smulders, M. J. M. (2008). Beyond coeliac disease toxicity: Detoxified and non-toxic grains. Pediatric and Adolescent Medicine,
12, 139-147.

Gilissen, L. J. W. J., van der Meer, I. M., \& Smulders, M. J. M. (2014). Reducing the incidence of allergy and intolerance to cereals. Journal of Cereal Science, 59, 337-353.

Gilissen, L. J. W. J., van der Meer, I. M., \& Smulders, M. J. M. (2016a). Why oats are safe and healthy for celiac disease patients. Medical Science, 4, 21.

Gilissen, L. J. W. J., van der Meer, I. M., \& Smulders, M. J. M. (2016b). Strategies to reduce or prevent wheat coeliac-immunogenicity and wheat sensitivity through food. In P. Koehler (Ed.), Proceedings of the 29th meeting of the Working Group on Prolamin Analysis and Toxicity 8-10 October 2015 Tulln, Austria (pp. 41-54). . http://www. wgpat.com/proceeding 29th.html. http://www.wgpat.com/proceeding 29th.pdf.

Goncharov, N. (2011). Genus Triticum L. taxonomy: The present and the future. Plant Systematics and Evolution, 295, 1-11.

Goryunova, S. V., Salentijn, E. M. J., Chikida, N. N., Kochieva, E. Z., van der Meer, I. M., Gilissen, L. J. W. J., \& Smulders, M. J. M. (2012). Expansion of the gamma-gliadin gene family in Aegilops and Triticum. BMC Evolutionary Biology, 12, 215.

Greco, L., Gobbetti, M., Auricchio, R., Di Mase, R., Landolfo, F., Paparo, F., ... Terrone, G. (2011). Safety for patients with celiac disease of baked goods made of wheat flour hydrolysed during food processing. Clinical Gastroenterology and Hepatology, 9, 24-29.

Gu, Y. Q., Crossman, C., Kong, X., Luo, M., You, F. M., Coleman-Derr, D., ... Anderson, O. D. (2004). Genomic organization of the complex $\alpha$-gliadin gene loci in wheat. Theoretical and Applied Genetics, 109, 648-657.

Gupta, P. K., Mir, R. R., Mohan, A., \& Kumar, J. (2008). Wheat genomics: Present status and future prospects. International Journal of Plant Genomics, 2008, 896451. http:// dx.doi.org/10.1155/2008/896451.

Gustafson, K. L. (2016). Impact of ingredients on quality and sensory characteristics of glutenfree baked goods. (K-State Research Exchange),

Hardy, M. Y., Tye-Din, J. A., \& Stewart, J. A. (2015). Ingestion of oats and barley in patients with celiac disease mobilizes cross-reactive $\mathrm{T}$ cells activated by avenin peptides and immuno-dominant hordein peptides. Journal of Autoimmunity, 56, $56-65$.

Hartmann, G., Koehler, P., \& Wieser, H. (2006). Rapid degradation of gliadin peptides toxic for coeliac disease patients by proteases from germinating cereals. Journal of Cereal Science, 44, 368-371.

Hollon, J., Puppa, E. L., Greenwald, B., Goldberg, E., Guerrerio, A., \& Fasano, A. (2015) Effect of gliadin on permeability of intestinal biopsy explants from celiac disease patients and patients with non-celiac gluten sensitivity. Nutrients, 7, 1565-1576.

Horstmann, S. W., Belz, M. C. E., Heitmann, M., Zannini, E., \& Arendt, E. A. (2016). Fundamental study on the impact of gluten-free starches on the quality of gluten-free model breads. Food, 5, 30.

Ishida, Y., Tsunashima, M., Hiei, Y., \& Komari, T. (2014). Wheat (Triticum aestivum L.). In K. Wang (Ed.), Methods in Molecular Biology(3rd ed.). Agrobacterium Protocols(pp. 189-198). New York: Springer.

Ishii, T., \& Araki, M. (2016). Consumer acceptance of food crops developed by genome editing. Plant Cell Reports, 35, 1507-1518.

Jones, H., Gosman, N., Horsnell, R., Rose, G. A., Everest, L. A., Bentley, A. R., ... Simek, R. (2013). Strategy for exploiting exotic germplasm using genetic, morphological, and environmental diversity: The Aegilops tauschii Coss. example. Theoretical and Applied Genetics, 126, 1793-1808.

Jupe, F., Witek, K., Verweij, W., Śliwka, J., Pritchard, L., Etherington, G. J., .. Cardle, L. (2013). Resistance gene enrichment sequencing (RenSeq) enables reannotation of the NB-LRR gene family from sequenced plant genomes and rapid mapping of resistance loci in segregating populations. Plant Journal, 76, 530-544.

Kanerva, P., Brinck, O., Sontag-Strohm, T., Salovaara, H., \& Loponen, J. (2011). Deamidation of gluten proteins and peptides decreases the antibody affinity in gluten analysis assays. Journal of Cereal Science, 53, 335-339.

Kasarda, D. D. (2013). Can an increase in celiac disease be attributed to an increase in the gluten content of wheat as a consequence of wheat breeding? Journal of Agricultural and Food Chemistry, 61, 1155-1159.

Kaukinen, K., Collin, P., Huhtala, H., \& Mäki, M. (2013). Long-term consumption of oats in adult celiac disease patients. Nutrients, 5, 4380-4389.

Kucek, L. K., Veenstra, L. D., Amnuaycheewa, P., \& Sorrells, M. E. (2015). A grounded guide to gluten: How modern genotypes and processing impact wheat sensitivity. Comprehensive Reviews in Food Science and Food Safety, 14. http://dx.doi.org/10. $1111 / 1541-4337.12129$.

Koning, F. (2012). Celiac disease: Quantity matters. Seminars in Immunopathology, 34, $541-549$.

Koning, F. (2015). Adverse effects of wheat gluten. Annals of Nutrition and Metabolism, 67(Suppl. 2), 8-14.

Krasileva, K. V., Vasquez-Gross, H. A., Howell, T., Bailey, P., Paraiso, F., Clissod, L., ... Dubcovsky, J. (2017). Uncovering hidden variation in polyploid wheat. Proceedings of the National Academy of Sciences of the United States of America, 114, E913-E921. http://dx.doi.org/10.1073/pnas.1619268114.

Kratzer, W., Kibele, M., Akinli, A., Porzner, M., Boehm, B. O., Koenig, W., ... Haenle, M. H. (2013). Prevalence of celiac disease in Germany: A prospective follow-up study. World Journal of Gastroenterology, 19, 2612-2620.

Kronberger, N., Wagner, W., \& Nagata, M. (2014). How natural is "more natural"? The role of method, type of transfer, and familiarity for public perceptions of cisgenic and transgenic modification. Science Communication, 36, 106-130.

Laass, M. W., Schmitz, R., Uhlig, H. H., Zimmer, K. P., Thamm, M., \& Koletzko, S. (2015). The prevalence of celiac disease in children and adolescents in Germany: Results from the KiGGS study. Deutsches Ärzteblatt International, 112, 553-560.

Lagrain, B., Brunnbauer, M., Rombouts, I., \& Koehler, P. (2013). Identification of intact high molecular weight glutenin subunits from the wheat proteome using combined liquid chromatography-electrospray ionization mass spectrometry. PloS One, $8 \mathrm{e} 58682$.

Laursen, L. (2016). Will Europe toast GM wheat for gluten sufferers? Nature Biotechnology, 
34, 369-371.

Lawrenson, T., Shorinola, O., Stacey, N., Li, C., Østergaard, L., Patron, N., ... Harwood, W. (2015). Induction of targeted, heritable mutations in barley and Brassica oleracea using RNA-guided Cas9 nuclease. Genome Biology, 16, 258.

Liang, Z., Chen, K., Li, T., Zhang, Y., Wang, Y., Zhao, Q., ... Gao, C. (2017). Efficient DNAfree genome editing of bread wheat using CRISPR/Cas9 ribonucleoprotein complexes. Nature Communications, 8, 14261.

Londono, D. M., van't Westende, W. P. C., Goryunova, S. V., Salentijn, E. M. J., van den Broeck, H. C., van der Meer, I. M., ... Smulders, M. J. M. (2013). Avenin diversity analysis of the genus Avena (oat). Relevance for people with celiac disease. Journal of Cereal Science, 58, 170-177.

Loponen, J. (2006). Prolamin degradation in sourdoughs. Academic dissertation. EKT series 1372. University of Helsinki.

Loponen, J., Sontag-Strohm, T., Venäläinen, J., \& Salovaara, H. (2007). Prolamin hydrolysis in wheat sourdoughs with differing proteolytic activities. Journal of Agricultural and Food Chemistry, 55, 978-984.

Loponen, J., Kanerva, P., Zhang, C., Sontag-Strohm, T., Salovaara, H., \& Gänzle, M. G. (2009). Prolamin hydrolysis and pentosan solubilization in germinated-rye sourdoughs determined by chromatographic and immunological methods. Journal of Agricultural and Food Chemistry, 57, 746-753.

Mäki, M., Mustalahti, K., Kokkonen, J., Kulmala, P., Haapalahti, M., Karttunen, T., Knip, M. (2003). Prevalence of celiac disease among children in Finland. New England Journal of Medicine, 348, 2517-2524. http://dx.doi.org/10.1056/NEJMoa021687.

McCallum, C. M., Comai, L., Greene, E. A., \& Henikoff, S. (2000). Targeting Induced Local Lesions IN Genomes (TILLING) for plant functional genomics. Plant Physiology, 123, 439-442.

Mitea, C., Salentijn, E. M., van Veelen, P., Goryunova, S. V., van der Meer, I. M., van den Broeck, H. C., ... Dekking, L. (2010). A universal approach to eliminate antigenic properties of alpha-gliadin peptides in celiac disease. PloS One, 5e15637.

Molberg, O., Uhlen, A. K., Jensen, T., Flaete, N. S., Fleckenstein, B., Arentz-Hansen, H., .. Sollid, L. M. (2005). Mapping of gluten T-cell epitopes in the bread wheat ancestors: Implications for celiac disease. Gastroenterology, 128, 393-401.

Morita, R., Kusaba, M., Iida, S., Yamaguchi, H., Nishio, T., \& Nishimura, M. (2009). Molecular characterization of mutations induced by gamma irradiation in rice. Genes \& Genetic Systems, 84, 361-370.

Mustalahti, K., Catassi, C., Reunanen, A., Fabiani, E., Heier, M., McMillan, S., ... Mäki, M. (2010). The prevalence of celiac disease in Europe: Results of a centralized, international mass screening project. Annals of Medicine, 42, 587-595.

Oladosu, Y., Rafii, M. Y., Abdullah, N., Hussin, G., Ramli, A., Rahim, H. A., ... Usman, M. (2016). Principle and application of plant mutagenesis in crop improvement: A review. Biotechnology \& Biotechnological Equipment, 30, 1-16.

Payne, P. I., Jackson, E. A., \& Holt, L. M. (1984). The association between $\gamma$-gliadin 45 and gluten strength in durum wheat varieties: A direct causal effect or the result of genetic linkage? Journal of Cereal Science, 2, 73-81.

Petersen, J., Montserrat, V., Mujico, J. R., Loh, K. L., Beringer, D. X., van Lummel, M., van Bergen, J. (2014). T-cell receptor recognition of HLA-DQ2-gliadin complexes associated with celiac disease. Nature Structural \& Molecular Biology, 21, 480-488.

Petersen, J., Kooy-Winkelaar, Y., Loh, K. L., Tran, M., van Bergen, J., Koning, F., ... Reid, H. H. (2016). Diverse T cell receptor gene usage in HLA-DQ8-associated celiac disease converges into a consensus binding solution. Structure, 24, 1643-1657.

Pistón, F., Gil-Humanes, J., Rodríguez-Quijano, M., \& Barro, F. (2011). Down-regulating gamma-gliadins in bread wheat leads to non-specific increase in other gluten proteins and has no major effect on dough gluten strength. PloS One, 6e24754.

Ratcliff, F., Harrison, B. D., \& Baulcombe, D. C. (1997). A similarity between viral defence and gene silencing in plants. Science, 276, 1558-1560.

Reif, J. C., Zhang, P., Dreisigacker, S., Warburton, M. L., van Ginkel, M., Hoisington, D., Melchinger, A. E. (2005). Wheat genetic diversity trends during domestication and breeding. Theoretical and Applied Genetics, 110, 859-864.

Rewers, M. (2005). Epidemiology of celiac disease: What are the prevalence, incidence, and progression of celiac disease? Gastroenterology, 128, S47-S51.

Risacher, T., Craze, M., Bowden, S., Paul, W., \& Barsby, T. (2009). Highly efficient Agrobacterium-mediated transformation of wheat via In Planta inoculation. In H. D. Jones, \& P. R. Shewry (Vol. Eds.), Methods in molecular biology, transgenic wheat, barley and oats. 478, (pp. 115-124).

Salentijn, E. M. J., Goryunova, S. V., Bas, N., van der Meer, I. M., van den Broeck, H. C., Bastien, T., ... Smulders, M. J. M. (2009). Tetraploid and hexaploid wheat varieties reveal large differences in expression of alpha-gliadins from homoeologous Gli-2 loci. BMC Genomics, 10, 48.

Salentijn, E. M. J., Mitea, D. C., Goryunova, S. V., van der Meer, I. M., Padioleau, I., Gilissen, L. J. W. J., ... Smulders, M. J. M. (2012). Celiac disease T-cell epitopes from gamma-gliadins: Immunoreactivity depends on the genome of origin, transcript frequency, and flanking protein variation. BMC Genomics, 13, 277.

Salentijn, E. M. J., Esselink, D. G., Goryunova, S. V., van der Meer, I. M., Gilissen, L. J. W. J., \& Smulders, M. J. M. (2013). Quantitative and qualitative differences in celiac disease epitopes among durum wheat varieties identified through deep RNA amplicon sequencing. BMC Genomics, 14, 905.

Saturni, L., Ferretti, G., \& Bacchetti, T. (2010). The gluten-free diet: Safety and nutritional quality. Nutrients, 2, 16-34.

Schaart, J. G., van de Wiel, C. C. M., Lotz, L. A. P., \& Smulders, M. J. M. (2016) Opportunities for products of new plant breeding techniques. Trends in Plant Science, 21, 438-449.

Schenk, M. F., Fischer, A. R. H., Frewer, L. J., Gilissen, L. J. W. J., Jacobsen, E., \& Smulders, M. J. M. (2008). The influence of perceived benefits on acceptance of GM applications for allergy prevention. Health, Risk and Society, 10, 263-282.

Schenk, M. F., van der Maas, M. P., Smulders, M. J. M., Gilissen, L. J. W. J., Fischer, A. R., van der Lans, I. A., ... Frewer, L. J. (2011). Consumer attitudes towards hypoallergenic apples that alleviate mild apple allergy. Food Quality and Preference, 22, 83-91.

Scherf, K. A., Wieser, H., \& Koehler, P. (2016). Improved quantitation of gluten in wheat starch for celiac disease patients by gel-permeation high-performance liquid chromatography with fluorescence detection (GP-HPLC-FLD). Journal of Agricultural and Food Chemistry, 64, 7622-7631.

Schwalb, T., Wieser, H., \& Koehler, P. (2012). Studies on the gluten-specific peptidase activity of germinated grains from different cereal species and cultivars. European Food Research and Technology, 235, 1161-1170.

Shewry, P. R. (2009). Wheat. Journal of Experimental Botany, 60, 1537-1553. http://dx. doi.org/10.1093/jxb/erp058.

Shewry, P. R., Halford, N. G., \& Lafiandra, D. (2003). The genetics of wheat gluten proteins. In J. C. Hall, J. C. Dunlap, \& T. Friedman (Vol. Eds.), Advances in genetics. 49, (pp. 111-184). Academic Press.

Shewry, P. R., D'Ovidio, R., Lafiandra, D., Jenkins, J. A., Mills, E. N. C., \& Bekes, F. (2009). Wheat grain proteins. In K. Khan, \& P. R. Shewry (Eds.), Wheat: Chemistry and Technology (pp. 223-298). (4th ed.). St. Paul, M.N., U.S.A.: A.A.C.C.

Shewry, P. R., \& Tatham, A. S. (2016). Improving wheat to remove coeliac epitopes but retain functionality. Journal of Cereal Science, 67, 12-21.

In Shu, Q. Y., Forster, B. P., \& Nakagawa, H. (Eds.), (2011). Plant mutation breeding and biotechnologyRome, Italy: FAO (ISBN 978-92-5-105000-0).

Smulders, M. J. M., Jouanin, A., Schaart, J., Visser, R. G. F., Cockram, J., Leigh, F., .. Gilissen, L. J. W. J. (2015). Development of wheat varieties with reduced contents of celiac-immunogenic epitopes through conventional and GM strategies. In P. Koehler (Ed.), Proceedings of the 28th meeting of the Working Group on Prolamin Analysis and Toxicity, 25-27 September 2014, Nantes, France (pp. 47-56). . http://www.wgpat. $\mathrm{com} /$ proceeding_28th.html.

Sollid, L. M., Qiao, S. W., Anderson, R. P., et al. (2012). Nomenclature and listing of celiac disease relevant gluten T-cell epitopes restricted by HLA-DQ molecules. Immunogenetics, 64, 455-460.

Spaenij-Dekking, L., Kooy-Winkelaar, Y., van Veelen, P., Drijfhout, J. W., Jonker, H., van Soest, L., ... Koning, F. (2005). Natural variation in toxicity of wheat: Potential for selection of nontoxic varieties for celiac disease patients. Gastroenterology, 129, 797-806.

Sprink, T., Eriksson, D., Schiemann, J., \& Hartung, F. (2016). Regulatory hurdles for genome editing: Process- vs. product-based approaches in different regulatory contexts. Plant Cell Reports, 35, 1493-1506.

Stenman, S. M., Lindfors, K., Venäläinen, J. I., Hautala, A., Männistö, P. T., GarciaHorsman, J. A., ... Kaukinen, K. (2010). Degradation of celiac disease-inducing rye secalin by germinating cereal enzymes: Diminishing toxic effects in intestinal epithelial cells. Clinical and Experimental Immunology, 161, 242-249.

Sutton, K. H., Simmons, L. D., Cummack, J. B., \& Roberts, S. J. (2015). Production of flours with reduced epitope content using milling technology. Cereal Chemistry, 93, 352-356.

Tanner, G. J., Blundell, M. J., Colgrave, M. L., \& Howitt, C. A. (2016). Creation of the first ultra-low gluten barley (Hordeum vulgare L.) for coeliac and gluten-intolerant populations. Plant Biotechnology Journal, 14, 1139-1150.

Tye-Din, J. A., Stewart, J. A., Dromey, J. A., Beissbarth, T., van Heel, D. A., Tatham, A., .. Hill, A. V. (2010). Comprehensive, quantitative mapping of T cell epitopes in gluten in celiac disease. Science Translational Medicine, 2, 41ra51.

Uhde, M., Ajamian, M., Caio, G., De Giorgio, R., Indart, A., Green, P. H., ... Alaedini, A. (2016). Intestinal cell damage and systemic immune activation in individuals reporting sensitivity to wheat in the absence of coeliac disease. Gut. http://dx.doi. org/10.1136/gutjnl-2016-311964.

USDA (2017). Importation, interstate movement, and environmental release of certain genetically engineered organisms. A proposed rule by the Animal and Plant Health Inspection Service on 01/19/2017. Document Citation 82 FR 7008; Document Number 2017-00858https://www.federalregister.gov/documents/2017/01/19/2017-00858/ importation-interstate-movement-and-environmental-release-of-certain-geneticallyengineered.

van de Wiel, C. C. M., Schaart, J. G., Lotz, L. A. P. \& Smulders, M. J. M. (2017). New traits in crops produced by genome editing techniques based on deletions. Plant Biotechnology Reports, 11, 1-8. http://dx.doi.org/10.1007/s11816-017-0425-z.

van den Broeck, H. C., van Herpen, T. W. J. M., Schuit, C., Salentijn, E. M. J., Dekking, L., Bosch, D., ... van der Meer, I. M. (2009). Removing celiac disease-related gluten proteins from bread wheat while retaining technological properties: A study with Chinese Spring deletion lines. BMC Plant Biology, 9, 41.

van den Broeck, H. C., de Jong, H. C., Salentijn, E. M. J., Dekking, L., Bosch, D., Hamer, R J., ... Smulders, M. J. M. (2010). Presence of celiac disease epitopes in modern and old hexaploid wheat varieties: Wheat breeding may have contributed to increased prevalence of celiac disease. Theoretical and Applied Genetics, 121, 1527-1539.

van den Broeck, H. C., Hongbing, C., Lacaze, X., Dusautoir, J. C., Gilissen, L. J. W. J., Smulders, M. J. M., \& van der Meer, I. M. (2010). In search of tetraploid wheat accessions reduced in celiac disease-related gluten epitopes. Molecular BioSystems, 6, 2206-2213.

van den Broeck, H. C., Gilissen, L. J. W. J., Smulders, M. J. M., van der Meer, I. M., \& Hamer, R. J. (2011). Dough quality of bread wheat lacking alpha-gliadins with celiac disease epitopes and addition of celiac-safe avenins to improve dough quality. Journal of Cereal Science, 53, 206-216.

van den Broeck, H. C., Cordewener, J. H., Nessen, M. A., America, A. H., \& van der Meer, I. M. (2015). Label free targeted detection and quantification of celiac disease immunogenic epitopes by mass spectrometry. Journal of Chromatography A, 1391, 60-71.

van Herpen, T. W. J. M., Goryunova, S. V., van der Schoot, J., Mitreva, M., Salentijn, E. M. J., Vorst, O., ... Vosman, B. (2006). Alpha-gliadin genes from the A, B and D genomes of wheat contain different sets of celiac disease epitopes. BMC Genomics, 7, 1. 
van Herpen, T. W. J. M., Riley, M., Sparks, C., Jones, H. D., Gritsch, C., Dekking, E. H., ... Shewry, P. R. (2008). Detailed analysis of the expression of an alpha-gliadin promoter and the deposition of alpha-gliadin protein during wheat grain development. Annals of Botany, 102, 331-342.

Vincentini, O., Borrelli, O., Silano, M., Gazza, L., Pogna, N., Luchetti, R., \& De Vincenzi, M. (2009). T-cell response to different cultivars of farro wheat, Triticum turgidum ssp. dicoccum, in celiac disease patients. Clinical Nutrition, 28, 272-277.

Vriezinga, S. L., Schweizer, J. J., Koning, F., \& Mearin, M. L. (2015). Coeliac disease and gluten-related disorders in childhood. Nature Reviews Gastroenterology \& Hepatology, 12, 527-536. http://dx.doi.org/10.1038/nrgastro.2015.98.

Walter, T., Wieser, H., \& Koehler, P. (2014). Degradation of gluten in wheat bran and bread drink by means of a proline-specific peptidase. Journal of Nutrition \& Food Sciences, 4, 293.

Wang, J., Luo, M. C., Chen, Z., You, F. M., Wei, Y., Zheng, Y., \& Dvorak, J. (2013). Aegilops tauschii single nucleotide polymorphisms shed light on the origins of wheat D-genome genetic diversity and pinpoint the geographic origin of hexaploid wheat. New Phytologist, 198, 925-937.

Wang, Y., Cheng, X., Shan, Q., Zhang, Y., Liu, J., Gao, C., \& Qiu, J.-L. (2014). Simultaneous editing of three homoeoalleles in hexaploid bread wheat confers heritable resistance to powdery mildew. Nature Biotechnology, 32, 947-951.

Waterhouse, P. M., \& Helliwell, C. A. (2003). Exploring plant genomes by RNA-induced gene silencing. Nature Reviews Genetics, 4, 29-38.

Weegels, P. L., van de Pijpekamp, A. M., Graveland, A., Hamer, R. J., \& Schofield, J. D. (1996). Depolymerisation and re-polymerisation of wheat glutenin during dough processing. I. Relationships between glutenin macropolymer content and quality parameters. Journal of Cereal Science, 23, 103-111.
Wen, S., Wen, N., Pang, J., Langen, G., Brew-Appiah, R. A., Mejias, J. H., ... Zemetra, R. S. (2012). Structural genes of wheat and barley 5-methylcytosine DNA glycosylases and their potential applications for human health. Proceedings of the National Academy of Sciences of the United States of America, 109, 20543-20548.

Wu, C. H., Nakai, S., \& Powrie, W. D. (1976). Preparation and properties of acidsolubilized gluten. Journal of Agricultural and Food Chemistry, 24, 504-510.

Wu, H., Sparks, C., Amoah, B., \& Jones, H. D. (2003). Factors influencing successfu Agrobacterium-mediated genetic transformation of wheat. Plant Cell Reports, 21, 659-668.

Wu, H., Doherty, A., \& Jones, H. D. (2008). Efficient and rapid Agrobacterium-mediated genetic transformation of durum wheat (Triticum turgidum L. var. durum) using additional virulence genes. Transgenic Research, 17, 425-436.

Zanini, B., Petroboni, B., Not, T., Di Toro, N., Villanacci, V., Lanzarotto, F., ... Lanzini, A. (2013). Search for atoxic cereals: A single blind, cross-over study on the safety of a single dose of Triticum monococcum, in patients with celiac disease. BMC Gastroenterology, 13, 92

Zhang, Y., Liang, Z., Zong, Y., Wang, Y., Liu, J., Chen, K., ... Gao, C. (2016). Efficient and transgene-free genome editing in wheat through transient expression of CRISPR/Cas9 DNA or RNA. Nature Communications, 7, 12617. http://dx.doi.org/10.1038/ ncomms12617.

Zhou, H., Liu, B., Weeks, D. P., Spalding, M. H., \& Yang, B. (2014). Large chromosoma deletions and inheritable small genetic changes induced by CRISPR/Cas9 in rice. Nucleic Acids Research, 42, 10903-10914. http://dx.doi.org/10.1093/nar/gku806. Zuidmeer, L., Goldhahn, K., Rona, R. J., Gislason, D., Madsen, C., Summers, C., ... McBride, D. (2008). The prevalence of plant food allergies: A systematic review. Journal of Allergy and Clinical Immunology, 121, 1210-1218. 